\section{Archivos y video: no lo hemos comprendido todo}

Mariela Cantú *

Resumen: El presente artículo propone adentrarse en los cambios generados por las tecnologías digitales y la circulación en Internet en los archivos audiovisuales en general, y a los de video en particular. Frente a una vertiginosa mudanza de soportes de lo analógico hacia lo digital en pos de la salvaguarda de las imágenes, buscaremos analizar el impacto de la digitalización, la circulación en red y el streaming en este proceso, estudiando el caso específico del archivo on-line y base de datos Arca Video Argentino, proyecto llevado a cabo por la autora de este escrito.

En particular, intentaremos plantear la problemática de la circulación en Internet como una posible condición de imposibilidad de los archivos, en la medida en que la inmediatez y la pronta desactualización de la información circulante tanto como de la tecnología que la soporta obliga a considerar un nuevo concepto de archivo audiovisual contemporáneo, desapegado tal vez de la función de salvaguarda física de los bienes que resguarda.

Palabras clave: archivo - autorreflexividad - digitalizacion - internet - video.

[Resúmenes en inglés y portugués en la página 106]

${ }^{(*)}$ Licenciada y Profesora en Comunicación Audiovisual (FBA-UNLP, Argentina). Investigadora y curadora en Artes y Medios Audiovisuales. Se ha desempeñado como docente en la Universidad de Buenos Aires (UBA), la Universidad Nacional de La Plata (UNLP), el Instituto Universitario Nacional del Arte (IUNA) y la Universidad del Cine (FUC).

"Una memoria total es una memoria anestesiada" Chris Marker, Sans Soleil.

¿Georges Perec? ¿Paolo Cherchi Usai? Puede haber sido Clarice Lispector. ¿O acaso Jacques Rancière? Tal vez Lydia Flem...o Sándor Márai. Reviso los últimos libros que leí buscando al autor de una cita (una de esas que resumen de una manera mágica y perfecta algo que nos aletea en la cabeza, y que siempre otro parece haber sabido expresar antes, y mucho mejor). Mirando un monte de libros y papeles desparramados, dudo: ¿la habré leído en un libro o la habré visto en una película? Miro notas y más notas. Miro por la ventana, miro la pared blanca. Google tampoco ayuda. Y si está en algún $p d f$ dentro de mi computadora, 
no estoy eligiendo las palabras correctas para encontrarla. La cita no quiere revelar su origen. De ella sólo quedan unas palabras escritas hace semanas en la pizarra que cuelga arriba del escritorio.

Es perfecto, pienso. Escribo un texto sobre los archivos audiovisuales, sobre su función de salvaguarda del paso del tiempo, sobre su pretensión de permanencia. Y el artículo empieza con un olvido.

La cita sigue sin aparecer. En tinta de marcador negro (al agua), las únicas palabras manuscritas que dan cuenta de una porción de su existencia dicen: "Recordar que se olvida". $Y$ en vista de esta pequeña experiencia, no puedo sino preguntarme (con el atrevimiento que hace falta cuando no se conoce de antemano una respuesta): ¿cuál, sino esa, podría ser entonces la función de los archivos?

Una de las más fascinantes e imperecederas fantasías humanas (aún hoy, a pesar de todas nuestras derrotas) radica en la creencia de un mundo que puede ser ordenado, clasificado y así, en última instancia, dominado. Las imágenes (técnicas y artesanales), han participado de esta carrera procurando retratar esos universos que nos rodean para acercarse un poco más a su comprensión: basta considerar las pinturas rupestres que podían servir para simular potenciales escenas de caza ${ }^{1}$, los exhaustivos estudios de Leonardo sobre la anatomía del cuerpo humano o el vuelo de las aves, la descomposición del movimiento en las fotografías de Edward Muybridge, etc ${ }^{2}$. En este sentido, podríamos sugerir toda una lectura sobre la historia de las imágenes en clave de un inventarío posible de objetos, representados a través de distintas técnicas: la pintura, la fotografía, el grabado, la televisión, el cine, etc.

Pero además de esas representaciones, ese afán de ordenamiento del mundo involucra también la domesticación de la memoria. La cronología, la causalidad, las periodizaciones, no hacen más que prolongar aquella ilusión de un encabalgamiento sucesivo de hechos que apuntan a un fin último, y que pueden por lo tanto ser leídos retrospectivamente para hallar en ellos un sentido.

Es aquí donde el archivo se hace presente, en la medida en que su concepto (y su labor) proponen un ordenamiento, un discurso y, en última instancia, una forma de contacto con el pasado y con las posibles memorias que pueden generarse a partir de él. En este sentido, quisiera prolongar ciertas ideas que comencé a esbozar en un artículo de reciente publicación (Cantú, 2012), en el que comenzaba planteando tres niveles de preservación de la memoria (audio)visual: el del deseo de conservar el mundo a través de las imágenes; el de conservar las propias imágenes, en tanto también son estas objetos materiales sometidos al desgaste y por ende, a la desaparición; y el del cuidado hacia los propios archivos que procuran evitar que esas imágenes caigan en el deterioro y la muerte. Me focalizaré aquí sobre todo en este último nivel, partiendo de la idea que los archivos definen nuestro contacto con el pasado a través de sus propias tecnologías (y no sólo las de las imágenes que ellos conservan) proponiendo así una interpretación de ese pasado. Y pensando también en el modo en que la digitalización como proceso contemporáneo que absorbe los medios anteriores, así como la circulación en la red, pueden haber modificado -y de qué maneras particulares- nuestra definición de archivo.

Para ello, me serviré del caso específico del archivo on-line y base de datos Arca Video Argentino (http://arcavideoargentino.com.ar), proyecto que comencé en el año 2008, par- 
tiendo de la necesidad de pensar los archivos de obras de arte en el sentido de la recreación de una experiencia estética (Rolnik) (y no sólo como un muestrario de documentos o bienes culturales en general), mediante la materialización de un archivo autorreflexivo. "Embalsamar el tiempo" era la respuesta que daba André Bazin cuando se preguntaba acerca de la ontología de la imagen fotográfica (Bazin, 1990). Mediante esa fórmula, destacaba en ese medio no sólo el irremediable deseo de retratar una porción de mundo que iba inevitablemente a desaparecer, sino de hacerlo en un soporte material que se volvería luego un objeto preciado, en la medida en que garantizaba la conservación de esa imagen. No obstante, el advenimiento del tercer milenio parece haber desplazado esa función de salvaguarda del pasado hacia una suerte de extensión del presente, probablemente ligada a la instantaneidad y producción profusa que es casi una marca de la imagen digital. La omnipresencia de las cámaras digitales en cualquier tipo de evento, las tomas fotográficas acompañadas del pedido de ver "cómo salimos", o la transformación de cualquier situación cotidiana en una sesión de fotos parecerían sugerir que el acto mismo de la toma de fotos -su cualidad performática - se ha vuelto la parte fundamental de la práctica fotográfica y la imagen resultante, entonces, un producto casi accesorio.

Hace pocos días conversaba con mi sobrino de 16 años sobre una serie de fotos que había subido a una red social en Internet. Luego de mis comentarios, me sorprendió recibir la recomendación de no mirar un álbum de fotos en su perfil de Facebook, ya que esas imágenes “eran viejas” y por tanto, carentes ya de cualquier interés: las fotografías en cuestión habían sido tomadas hacía menos de un mes atrás.

Así como en estos ejemplos, podríamos aventurar que la digitalización ha tenido un claro impacto sobre el registro y la producción de las imágenes, incluso antes que en su circulación. Si las claves que parecían definir la representación visual están mudando, es claro que las formas de archivar esas imágenes tienen también que modificarse. Ahora bien, ¿qué ocurre cuando esos archivos contemporáneos deben lidiar con imágenes que no sólo los anteceden en el tiempo, sino que pertenecen a un estadio tecnológico anterior? Y si el cometido del archivo es precisamente conservar del deterioro ocasionado por el paso del tiempo, ¿es posible (o deseable) pensar en un archivo que modifique también tecnológicamente, las imágenes que archiva?

Dado que el foco principal de este escrito tiene que ver con los archivos de video (arte), es imperativo trazar ciertas coordenadas para aproximarnos a sus obras, lo cual no implica poner el acento en la cuestión de su especificidad ${ }^{3}$. Por el contrario, el video se ha caracterizado precisamente por la contaminación como una situación recurrente, tanto en los artistas que lo emplean (muchas veces, no provenientes de disciplinas audiovisuales), como en su misma base tecnológica. Ya que si bien podríamos colocarlo bajo el paraguas de la imagen electrónica, es difícil pensar al video por fuera de la multiplicidad de sus formatos (cintas de 2 pulgadas, de 1 pulgada, Betamax, U-Matic, VHS, Hi-8, Betacam, mini DV, DVCAM, Betacam digital o Digi Beta, D I, D II o el CG, el DVD, la HDD, etc.), así como de la necesaria mudanza de soportes para asegurar su supervivencia. Incluso dentro de la labor de preservación, es notable advertir que las técnicas de restauración de obras insisten en general en el trabajo sobre los originales: en la pintura o la escultura por ser obras únicas, pero también cuando hablamos de películas o fotografías, se busca operar sobre los negativos (para el caso de las imágenes reproducibles, lo más cercano a un original). El 
video es diverso en este sentido, ya que su pervivencia se ha visto vinculada sobre todo a la ausencia de esa obra material originaria: si bien tuvo que existir una primera copia en el momento de creación, su circulación y por lo tanto su existencia (dos coordenadas que al tratarse de un medio técnicamente reproducible aparecen prácticamente asociadas), han sido definidas por la imposibilidad de rastrear aquella copia primera, en pos de la multiplicación y la difusión.

En todo este proceso, la digitalización ha venido a agregar un nuevo soporte de migración de las obras, pues como decíamos, esta contaminación y mudanza era ya una condición necesaria de supervivencia del medio en la medida en que los diversos formatos iban (y van) quedando obsoletos. No obstante, intuyo que la idea sobre lo digital fagocitando todos los bienes culturales que lo precedieron no consigue superar cierto discurso celebratorio, y una confusa propuesta de democratización de la cultura ${ }^{4}$, que deja poco margen para analizar críticamente los procesos de digitalización como algo más que un destino (¿una condena?) ineludible.

Paradójicamente, esta necesidad de actualización permanente es la que genera esa sensación de obsolescencia, incluso en obras que no superan unos pocos años de realización 5 , creando una historia de un modo llamativamente vertiginoso. Pero un poco a contracorriente de esa percepción, me parece más interesante concebir a la digitalización como una interpretación (posible, cuestionable, reemplazable) del pasado, antes que como un presente irrefrenable y eterno. Entendido de esa manera, el universo de lo digitalizado pone en evidencia su carácter heterogéneo, pues estamos todavía lejos de haber alcanzado una uniformidad digital, a pesar que este medio parece haber siempre deseado borrar las diferencias entre soportes anteriores al convertir todo a ceros y unos. En consecuencia, tanto el objeto archivado (el video) como el propio archivo (digital) podrían manifestarse desde este punto de vista como los objetos inestables que realmente son, como territorios no domesticables, insistiendo antes que borrando esa convivencia múltiple de tecnologías y discursos.

En esta misma línea, podemos pensar otro proceso complementario a la digitalización, relacionado con la circulación de esas imágenes convertidas a lenguaje binario, en esa inconmensurable extensión que representa Internet. Los primeros años de nuestro contacto civil con la red (pues ante todo, Internet nació como un sistema de defensa de los Estados Unidos y no como un espacio de intercambio de información o un gigantesco archivo cultural) estuvieron marcados por una innegable fascinación y un frágil sueño que creía que todo podía encontrarse ahí. Poco a poco, aquella quimera fue cediendo frente a la evidencia de todo lo que ahí no estaba. Y no sólo faltaban los objetos no digitalizables, sino también los que, aún habiendo sido trascodifcados, se perdían en una galaxia de datos no consignados por los buscadores, en la imprecisión del lenguaje, en una coincidencia remota muy debajo de los enlaces patrocinados ${ }^{6}$. Bajo esta luz, estimo más adecuado considerar a la red como una potable conceptualización de nuestro enfrentamiento con lo inabarcable, mucho antes que como un territorio de disponibilidad, tan ingenua como pretendidamente absoluta.

En este sentido, y al contrario de los archivos que le precedieron, el archivo digitalizado y on-line no pareciera tener la voluntad de salvaguardar del paso del tiempo sino, ante todo, la función de rescatar de la superabundancia del propio presente. Y si bien existen 
otras razones históricas y políticas que explican nuestra actual y casi imperativa voluntad de archivo, me permito aventurar que nuestro cotidiano contacto con Internet contiene la potencialidad de volvernos (aún más) concientes de la inevitable pérdida de objetos e información a la que estamos sujetos diariamente.

Desde esta óptica, el archivo digitalizado y on-line estaría asociado (así como las fotos de mi sobrino) a la inmediatez y a la fugacidad del presente, antes que al resguardo del pasado. Ahora bien, de este modo, estaría planteando su propia condición de inexistencia, en la medida en que todo archivo necesita del paso del tiempo para poner en valor, para volver a ver, para desear encontrarse nuevamente con una imagen. Sucede algo curioso a este respecto, pues Internet es también, en cierto sentido, una acumulación de ruinas; de links que no funcionan, de información replicada, de datos desactualizados. Entonces, un archivo pensado en este contexto debe ser permanentemente actualizado (y actualizable). Entonces, un archivo pensado en este contexto deja de ser ese espacio anquilosado asociado al pasado, esa garantía de permanencia ilusoria, obligándonos a mirarlo y a pensarlo una y otra vez, con recurrencia. Otro modelo de archivo nos recuerda que no son sólo las obras que se archivan las que envejecen.

El proyecto Arca Video Argentino comenzó como un proyecto de investigación en el marco de la Universidad Nacional de La Plata en el año 20087. En sus inicios, este trabajo incluyó un recorrido tradicional que procuraba sondear las obras de video arte monocanales, producidas en Argentina y por argentinos fuera del país, desde el año 1980 hasta el 2009. Esta primera etapa incluyó entonces una labor de relevamiento en instituciones públicas y privadas que hubiesen generado muestras y/o festivales en torno al video durante ese período, partiendo de un recorte inicial de obras exhibidas únicamente en la ciudad de Buenos Aires.

Todo este recorrido comenzó a concretarse virtualmente (valga la paradoja) en la página web http://arcavideoargentino.com.ar/, buscando crear una base de datos con la información de las obras relevadas, tanto como un archivo on-line que permitiera visualizarlas (o algunas de ellas al menos). Dado que esta tarea comenzó como un proyecto individual y con recursos limitados, se hizo necesario solicitar copias de las obras a sus realizadores que ya hubiesen sido codificadas a formato digital (preferentemente archivos con extensión .avi o .mov sin compresión). Pero al recibir los primeros discos, pronto se hizo evidente que no todas las copias llegaban con una calidad de imagen uniforme, sino que por el contrario, los procesos de digitalización eran claramente variables de una a otra obra -sobre todo en aquellas que se encontraban originariamente en soporte analógico, y debieron ser entonces digitalizadas.

Sumado a ésto, una de las condiciones de exhibición de los videos propuesta a los realizadores fue la de hacerlos disponibles en un formato comprimido para que no pudieran ser descargadas y exhibidas en una calidad aceptable, para evitar así proyecciones no autorizadas. Como era de esperarse, todos estos pasos ocasionaron que la resolución de las imágenes fuese aún menor, insertando en muchos casos marcas de lo digital, como por ejemplo el pixelado.

Podríamos tomar el ejemplo del video La progresión de las catástrofes (Galuppo, 2004), de Gustavo Galuppo. Un rasgo recurrente en la obra de este realizador radica en la utilización de material de archivo, gran parte de las veces echando mano de la iconografía 
del cine clásico: de hecho, La progresión... comienza con un plano emblemático de The Quiet Man (Ford, 1952), de John Ford (la escena de la cachetada y el beso entre John Wayne y Maureen O’Hara que ilustró a su vez el afiche de la película), imagen que se repite insistentemente a lo largo del video con ralentizados variables. Ahora bien, estas escenas cinematográficas son habitualmente mixturadas en la obra de Galuppo con imágenes de otra procedencia, como por ejemplo registros en video, con cámaras web o fotográficas, material de archivo televisivo, etc., pero provocando toda una lectura alternativa a partir de la manipulación digital. Es decir, aquel material de archivo producido en un determinado contexto -histórico, político, narrativo, expresivo-, se ve desvirtuado y es el punto de partida de un nuevo discurso estético que, si bien se sirve de aquellas imágenes como materia prima, desprende un sentido diverso al que contenía originariamente (para el caso de La progresión...toda una lectura de las imágenes idílicas y las conceptualizaciones arbitrarias del amor romántico en el cine, desde Hollywood hasta los registros cotidianos de las películas caseras).

Pero si vemos este video on-line, no solamente aparecen las huellas de la manipulación digital operadas por Galuppo, sino también las de la compresión del archivo original, es decir, una textura de píxeles evidentes, que vienen a agregarse a la obra tal como fue concebida al momento de su realización.

En el artículo que disparó algunos de estos cuestionamientos citado al inicio, proponía que la tecnología empleada en una obra de video es también marca de una época, y debe por eso ser conservada:

Sucede que muchas veces, antes incluso de alcanzar la desaparición material que ataca al cine fotoquímico, el video migra de soporte. Signados por un presente en el que la hibridez constituye una constante en la creación audiovisual, sería posible inscribir a cada uno de esos soportes como marca de una época, casi como signo de los cambios físicos que se revelan con cada edad en el propio cuerpo (Cantú, 2012).

En este contexto, ¿implica la digitalización una suerte de traición a los originales? ¿Estamos invadiendo una obra y desestimando el potencial de sus intervenciones estético-tecnológicas? ¿Habrá llegado la hora de pensar en una ética de la digitalización?

Dado que estamos tratando aquí con obras de arte y no con simples datos o información que se digitaliza, es un buen momento para retomar algunas consideraciones de Suely Rolnik a este respecto:

Urge preguntarse acerca de las políticas de inventario, ya que son muchos los modos de abordar las prácticas artísticas que se pretende inventariar, no sólo desde el punto de vista técnico, sino también y fundamentalmente desde el punto de vista de su propia carga poética. Me refiero a la capacidad del dispositivo propuesto de crear las condiciones para que tales prácticas puedan activar experiencias sensibles en el presente, necesariamente distintas de las que se vivieron originariamente, pero con el mismo tenor de densidad crítica. Sin embargo, la problematización de este aspecto trae 
aparejados al menos otros dos bloques de preguntas. El primero se refiere al tipo de poéticas inventariadas: ¿Qué poéticas son éstas? ¿Tendrían aspectos comunes? ¿Estarían ubicadas en contextos históricos similares? ¿En qué consiste inventariar poéticas y en qué se diferenciaría esto de inventariar únicamente objetos y documentos? El segundo bloque de preguntas se refiere a la situación que engendra este furor de archivar: ¿Qué causa la emergencia de este deseo en el actual contexto? ¿Qué políticas de deseo sirven de impulso a las diferentes iniciativas de inventario y sus modos de presentación? (Rolnik, en Revista Estudios Visuales, n. 7).

Recrear el potencial discursivo y poético de una obra debiera ser el fin último de un archivo de obras de arte y de toda la tarea de conservación que en él se pone en marcha, favoreciendo el contacto entre esas obras y el espectador-consultante, permeado a su vez por la "densidad crítica" a la que se refiere Rolnik. En este contexto, sería atractivo pensar los efectos discursivos del digital, retomando la propuesta de Hal Foster cuando, analizando la tarea de André Malraux en El museo imaginario, señalaba que los efectos discursivos de la reproducción fotográfica no habían sido pensados hasta la década de 1930 (Foster, en http://60yearscurating.files.wordpress.com/2008/03/foster-archive.pdf). En El museo..., Malraux se tomaba el trabajo de reflexionar acerca de las nuevas configuraciones que ofrecía la fotografía en blanco y negro al acercar las obras pictóricas entre sí, creando nuevos vínculos tal vez impensados hasta el momento, cuando esas reproducciones fotográficas se unían en una misma página. Por eso para el autor, "la historia del arte después de cien años, desde que escapa a los especialistas, es la historia de aquello que es fotografiable" (Malraux, 1947).

Claramente, puede rastrearse en esta posición toda la influencia del inagotable Walter Benjamin cuando, lejos de denostar las artes reproducibles, encontraba en ellas una "conmoción de la tradición" y una posibilidad de mudanza en la percepción de su potencial destinatario. Si la autenticidad de la obra de arte había estado siempre ligada al énfasis en su "aquí y ahora", lo que la reproductibilidad técnica venía a combatir era entonces su "aura”, desligándola entonces de su función ritual:

...por primera vez en la historia universal, la reproductibilidad técnica emancipa a la obra artística de su existencia parasitaria en un ritual. La obra de arte reproducida se convierte, en medida siempre creciente, en reproducción de una obra artística dispuesta para ser reproducida. De la placa fotográfica, por ejemplo, son posibles muchas copias; preguntarse por la copia auténtica no tendría sentido alguno. Pero en el mismo instante en que la norma de la autenticidad fracasa en la producción artística, se trastorna la función íntegra del arte. En lugar de su fundamentación en un ritual aparece su fundamentación en una praxis distinta, a saber en la política (Benjamin, 1936).

A pesar de su iluminador punto de vista, es preciso recordar que todo este debate acontecía en torno a esa condición aurática de la obra de arte, sustraída por el cine respecto 
al teatro (el aquí y ahora de la representación escénica), siendo el público reemplazado por el aparato en el rodaje cinematográfico. Pero tal como comentábamos anteriormente, esa existencia como obra irrepetible que funda toda la idea de autenticidad y unicidad de la obra de arte $^{8}$ no es aplicable al video. No sólo porque, tanto como la fotografía y el cine, se funda precisamente en la reproductibilidad como base técnica de su praxis sino porque, a diferencia de aquellos otros dos medios, el video se ha definido por su impureza, tanto estética como tecnológica. En términos generales, los soportes fotoquímicos no han variado excesivamente desde sus comienzos, habiéndose estabilizado y estandarizado tecnológicamente casi desde su creación (exceptuando las mudanzas del nitrato al acetato, y hoy al poliéster, tres cambios ocurridos en más de cien años de vida), al menos hasta la llegada del (cine) digital.

En este marco, si tanto el video (cuyas incesantes mudanzas de soporte comentábamos anteriormente) como el universo de lo digital (que a pesar de su apariencia, no ha alcanzado ni parece tampoco perseguir ninguna fijación en cuanto a sus formatos) encuentran su efervescencia en la contaminación y la inestabilidad, podríamos sugerir que, antes que la creación de una "familia" y el acercamiento de las obras entre sí que Malraux veía en la relación de la fotografía y la pintura, la digitalización tiene la capacidad de enfatizar la heterogeneidad del video.

Si nos arriesgamos entonces a considerar los potenciales efectos discursivos del digital sobre la práctica de los archivos de video, sería posible considerar que el pixelado, el tamaño pequeño de las imágenes, el visionado en una pantalla de computador y no en una proyección o en un monitor, entre otras falencias, pone de relieve precisamente lo que está ausente en las obras. Entonces, lejos de homogeneizar y esconder las marcas del archivo digitalizado, estas huellas de la imagen contemporánea advierten sobre eso que todo archivo debería manifestar abiertamente: no me es dado mostrar las obras en su contexto original, no me es dado exhibir el pasado por fuera de la interpretación que sobre él propongo, no me es dado contar ninguna historia que no se refiera al presente.

Por supuesto, no es mi intención proponer con estas ideas la defensa de procesos técnicos de digitalización intencional o ingenuamente desacertados, así como tampoco la intromisión en los aspectos visuales y estéticos de una obra. Pero no deja de interesarme el modo en que estas prácticas fundan la duda sobre la autenticidad, que debiera ser la premisa de cualquier archivo audiovisual; como decía aquella cita nunca encontrada, la de "recordar que se olvida”.

Por otro lado, encuentro en esta cualidad autorreflexiva del archivo también una forma de alteridad frente al actual discurso ligado al marketing de lo digital, que propugna una obsoleta idea de novedad, como si todo aquello que lo precedió sólo pudiera tener existencia bajo la luz del código binario. En realidad, Walter Benjamin en 1936 y André Malraux en 1947 estaban ya trazando aproximaciones críticas a las posibles relecturas que un medio puede hacer de los anteriores. Para volver sobre Benjamin, en vano se aplicó por de pronto mucha agudeza para decidir si la fotografía es un arte (sin plantearse la cuestión previa sobre si la invención de la primera no modificaba por entero el carácter del segundo) (Benjamin, 1936).

No casualmente, ambos eligieron como su objeto de estudio a las obras de arte, y no simplemente cualquier otro bien cultural. Evidentemente, existía en esta elección la búsqueda 
del mismo desafío que conquista a Suely Rolnik cuando se pregunta por la posibilidad de recrear una experiencia estética, que tiene que ver, a mi entender, con una insistente pregunta por el espectador. Desde esta óptica, nos vemos obligados a enfrentarnos a un sujeto complejo, deseante, curioso, que en el decurso de su experiencia estética consigue desplazarse del lugar de consumidor o receptor diseñado para él por todo un cuestionable discurso que defiende a las "industrias culturales" como el único espacio de contacto con las manifestaciones contemporáneas de la cultura (comprar, poseer, desechar).

En este sentido, esta propuesta de trabajo autorreflexivo sobre el archivo, sobre la exploración de sus límites, sobre la asunción de sus condicionamientos y sobre la práctica de asumirse concientemente como un archivo de obras de arte debe indagar en la manifestación de la heterogeneidad de sus fuentes (la impureza del video), así como también en la transparencia de sus prácticas de salvaguarda.

Por eso, la digitalización puede ser un recurso interesante cuando permeabiliza la procedencia de las imágenes sobre las que acciona, y cuando consigue trascender los espacios de exhibición para los cuales las obras fueron inicialmente concebidas, como ocurre actualmente con las imágenes que encontramos en Internet. Como señalaba Benjamin, es posible imaginar que estas prácticas, antes que contradecir la lógica del archivo o de luchar para encajar en ella, puedan estar proponiendo otro modelo de preservación de las imágenes. “¿Existe de veras un dilema entre preservar los objetos y mostrarlos?” (Cherchi Usai, 2005), se pregunta Paolo Cherchi Usai, aludiendo a dos caras de un mismo proceso, que no son para nada excluyentes. Antiguamente, no sólo la materialidad de una obra sino la posibilidad de experimentarla estaban ligadas a su cualidad aurática y cultual: para muchos, la contemplación de un cuadro o una escultura podía acontecer sólo una vez en el transcurso de toda una vida, lo cual imponía a esa experiencia la obligación de sentirla casi como un acto de intensidad. Sucede que, a pesar de ser un medio reproducible, esto mismo acontece muchas veces con el video arte, una práctica artística que largamente se ha visto restringida a un circuito de festivales, muestras y espacios de arte específicos, que no siempre han sabido convocar la concurrencia (o el interés) de un público interesado.

Considerando la envergadura de un proyecto como el de Arca Video Argentino, no puedo considerar estas primeras etapas más que como un inicio. Claramente, la circulación y difusión de las obras que este archivo contiene fueron algunas de las razones principales para pensar en una existencia on-line, pero no creo que Internet tenga necesariamente que ser la única plataforma de exhibición de estos materiales. Antes bien, y siendo un archivo de obras de arte de un país ubicado en América Latina, son bien sabidas las limitaciones que tenemos respecto al acceso a la tecnología y a la red, pero no por eso preferimos caer en falsas dicotomías como las de original y copia, real y virtual, analógico y digital. Finalmente, "no tiene sentido si no se preserva algo no menos precioso que las imágenes en movimiento: el derecho a verlas. Ver es un arte en sí mismo.” (Cherchi Usai, 2005) Para concluir, quisiera retomar las palabras del inolvidable Chris Marker que abren este escrito, un realizador audiovisual fascinado para siempre por la posibilidad de memoria habilitada por las imágenes (no casualmente, la cita del inicio proviene de esa película sin límites llamada Sans Soleil) (Marker, 1983). La frase y la película no podrían haber casado con mayor maestría, pues nada ha estado más lejos de las búsquedas de Marker que la reivindicación de la totalidad, la defensa de lo universal, el propósito de lo absoluto. Por el 
contrario, también en películas como La Jetée (Marker, 1962) o en experimentos aún más inclasificables como Immemory (Marker, 1997), el tono recurrente que empleaba el realizador francés (y no me refiero a su voz) tuvo siempre que ver con la duda por lo que no es categorizable, por los espacios vacíos que dejan las preguntas, por los silencios que provoca una imagen cuando uno consigue realmente entregarse a ella. Por eso, se me ocurre pensar que el archivo no se trata de volver el pasado al presente, sino de colocar el acento en aquello que precisamente los divide. Finalmente, todo ese ansia de dominio sobre el mundo no puede responder más que a una ilusión de orden que no es sólo artificial, sino muchas veces, azaroso, arbitrario, contingente.

Si no hay un sentido, si no hay un todo que pueda ser reconstruido, uno de los mayores peligros que puede encarnar el archivo radica en pensarse como un refugio, como un espacio sedante en el que la mirada no pueda más que descansar. Uno de los mayores peligros del archivo: pensar que lo hemos comprendido todo (o que podemos hacerlo).

¿Para qué conservar entonces si el acceso al sentido no es revelado? Supongo que, como piensa Comolli respecto al cine, "para restablecer un sentido que todavía no está dado, que todavía no es posible, pero ya está inscrito, sin que se lo sepa, en lo que es filmado" (Comolli, 2010), es decir, filmar por "la promesa de un sentido". Conservar, archivar, mostrar, para saber de nuestros olvidos, para sorprendernos de nuestros recuerdos, para nunca dejar de crear(nos) a través de la memoria.

\section{Notas}

1. En Cave of Forgotten Dreams, Werner Herzog sugiere una función de estas pinturas no solamente ligada a la representación pictórica o a un uso ritual, sino como formas en que los mayores enseñaban a los niños a reconocer animales en distintos escenarios y posiciones, para mejorar su técnica de caza.

2. No se trata aquí solamente de entender a las imágenes en su papel icónico o indicial; es decir que estas reflexiones pueden aplicarse tanto a las imágenes técnicas como artesanales, y a las figurativas tanto como a las abstractas. En última instancia, se trata de pensar a la representación visual como una forma de abordaje de nuestra comprensión sobre el mundo, haya sido este registrado de un real o no.

3. En "Convergencia y Divergencia de los medios", Arlindo Machado, destaca que esta noción de especificidad fue antes defendida desde una postura teórica y analítica, sobre todo en la década del 80, antes que planteada por las obras en sí mismas.

4. Esto se torna evidente cuando consideramos que gran parte de nuestro acceso a la tecnología está mediado por las corporaciones, la adquisición de objetos de consumo y por lo tanto, la necesidad de suponer de dinero para su consumo. Lo cual vuelve interesante propuestas como las del copy-left, el software libre y open-source, el trabajo sobre tecnologías obsoletas, etc., tendencias cada vez más crecientes en América Latina.

5. La última edición del Festival Videobrasil el año pasado llamó mi atención, ya que el HD parecía haber impuesto un estándar en la producción de las obras, dejando de lado casi por completo la elección de otros soportes en video como parte de otra posible exploración estética. http://www.videobrasil.org.br/17/ 
6. Al respecto, ver Reischel, G. El engaño Google.

7. Posibilitado por el otorgamiento de una Beca de Perfeccionamiento de la Universidad Nacional de La Plata, y dirigida por el Dr. Eduardo Russo.

8. No obstante, es interesante repasar la óptica apuntada por Rosalind Krauss respecto a esa aparente dicotomía original/copia en las obras de arte -refiriéndose en particular a la obra de Rodin- en La originalidad de la Vanguardia: una Repetición Postmoderna.

\section{Referencias Bibliográficas}

Bazin, A. (1990). Ontología de la imagen fotográfica en ¿Qué es el Cine?. Madrid: Ediciones Rialp.

Benjamin, W. (1936). La obra de arte en la época de la reproductibilidad técnica en Discursos Interrumpidos (1994) Buenos Aires: Planeta - Agostini.

Cantú, M. (2012). La historia en (las) imágenes: memoria, archivo, video en La Ferla, J. y Reynal, S. (comp.) Territorios Audiovisuales: cine, video, televisión, documental, instalación, nuevas tecnologías, paisajes mediáticos. Buenos Aires: Libraria.

Cherchi Usai, P. (2005). La muerte del cine. Barcelona: Laertes.

Comolli, J. (2010). Documento y Espectáculo en La Ferla, J. (comp.) Arte, ciencia y tecnología: un panorama crítico. Buenos Aires: Espacio Fundación Telefónica.

Foster, H. The Archive without Museums. Disponible en http://60yearscurating.files.wor dpress.com/2008/03/foster-archive.pdf

Krauss, R. La originalidad de la Vanguardia: una repetición postmoderna. Disponible en http://www.ddooss.org/articulos/textos/Rosalind_Krauss.htm

Machado, A. Convergencia y Divergencia de los medios. Disponible en http://www.hamal web.com.ar/Textos/Machado-convergencia-y-divergencia.pdf

Malraux, A. (1947). Le museé imaginaire. Paris, Albert Skira Editeur.

Reischel, G. (2009). El engaño Google. (1 ${ }^{\text {a }}$ ed.) Buenos Aires: Sudamericana.

Rolnik, S. Furor de archivo. En Revista Estudios Visuales, n.7. Disponible en http://estudio svisuales.net/revista/pdf/num7/08_rolnik.pdf

\section{Filmografía}

Ford, J. (1952). The Quiet Man.

Galuppo, G. (2004). La progresión de las catástrofes.

Herzog, W. (2010). Cave of Forgotten Dreams.

Marker, C. (1997). Immemory [CD-ROM interactivo].

(1983). Sans Soleil.

(1962). La Jetée. 
Summary: This article proposes to explore the changes brought by digital technologies and the Internet circulation of audiovisual files and in particular of video files. Faced with a dizzying media moving from analogical to digital -and having in mind the safeguarding of images- we seek to analyze the impact of digitalization, circulation network and streaming in this process, studying the specific case of the online file database Arca Video Argentino, a project conducted by the author of this paper.

In particular, we will try to raise the issue of internet traffic as a possible condition of impossibility of the files, to the extent that the immediacy and rapid obsolescence of current information as well as the technology that supports it, demands to have in consideration a new concept of contemporary audiovisual archive, perhaps detached from the physical backup function.

Keywords: digitization - file database - internet - self-reflexivity - video.

Resumo: $\mathrm{O}$ artigo propõe adentrar-se nas mudanças geradas pelas tecnologias digitais e a circulação na Internet nos arquivos audiovisuais em geral, e aos de vídeo em particular. Frente a uma vertiginosa mudança de suportes do analógico até o digital em pos da salvaguarda das imagens, procuraremos analisar o impacto da digitalização, a circulação em rede e o streaming neste processo, estudando o caso específico do arquivo on-line e base de dados Arca Vídeo Argentino, projeto feito pela autora deste escrito.

Em particular, intentaremos explicar a problemática da circulação em Internet como uma possível condição de impossibilidade dos arquivos, na medida em que a rápida desatualização da informação circulante tanto como da tecnologia que a suporta obriga a considerar um novo conceito de arquivo audiovisual contemporâneo, despegado talvez da função de salvaguarda física dos bens que resguarda.

Palavras chave: arquivo - auto-reflexão - digitalização - Internet - vídeo. 